\title{
Conventional and phenomics characterization provides insight into the diversity and relationships of hypervariable scarlet (Solanum aethiopicum L.) and gboma (S. macrocarpon L.) eggplant complexes
}

\author{
Mariola Plazas, Isabel Andújar, Santiago Vilanova, Pietro Gramazio, F. Javier Herraiz and \\ Jaime Prohens *
}

Instituto de Conservación y Mejora de la Agrodiversidad Valenciana, Universitat Politècnica de València, València, Spain

\author{
Edited by: \\ Diego Rubiales, Consejo Superior de \\ Investigaciones Cientificas, Spain \\ Reviewed by: \\ Juan B. Alvarez, Universidad de \\ Córdoba, Spain \\ Xavier Raymond Richard Sirault, \\ Commonwealth Scientific and \\ Industrial Research Organisation, \\ Australia \\ John Hancock, University of \\ Cambridge, UK \\ *Correspondence: \\ Jaime Prohens, Instituto de \\ Conservación y Mejora de la \\ Agrodiversidad Valenciana, \\ Universitat Politècnica de València, \\ Camino de Vera 14, 46022 València, \\ Spain \\ e-mail: jprohens@btc.upv.es
}

Scarlet (Solanum aethiopicum) and gboma (S. macrocarpon) eggplants are major vegetable crops in sub-Saharan Africa. Together with their respective wild ancestors (S. anguivi and $S$. dasyphyllum) and intermediate cultivated-wild forms they constitute the so-called scarlet and gboma eggplant complexes. We used conventional descriptors and the high-throughput phenomics tool Tomato Analyzer for characterizing 63 accessions of the scarlet eggplant complex, including the four $S$. aethiopicum cultivar groups (Aculeatum, Gilo, Kumba, and Shum), Intermediate S. aethiopicum-S. anguivi forms, and S. anguivi, and 12 cultivated and wild accessions of the gboma eggplant complex. A large diversity was found between both complexes, showing that they are very well differentiated from each other. Within the scarlet eggplant complex, many significant differences were also found among cultivar groups, but more differences were found for fruit traits evaluated with Tomato Analyzer than with conventional descriptors. In particular, Tomato Analyzer phenomics characterization was useful for distinguishing small fruited groups (Shum, Intermediate, and $S$. anguivi), as well as groups for which few or no significant differences were observed for plant traits. Multivariate principal components analysis (PCA) separated well all groups, except the Intermediate group which plotted between $S$. anguivi and small fruited $S$. aethiopicum accessions. For the gboma eggplant complex, S. dasyphyllum was clearly distinguished from $S$. macrocarpon and an important diversity was found in the latter. The results have shown that both complexes are hypervariable and have provided insight into their diversity and relationships. The information obtained has important implications for the conservation and management of genetic resources as well as for the selection and breeding of both scarlet and gboma eggplants.

Keywords: crop complexes, cultivar groups, descriptors, phenomics, Solanum aethiopicum, Solanum macrocarpon, Tomato Analyzer

\section{INTRODUCTION}

The scarlet (Solanum aethiopicum L.) and gboma (S. macrocarpon L.) eggplants are two cultivated African vegetable crops locally important in its region of origin in tropical sub-Saharan Africa (Lester et al., 1990; Schippers, 2000; Lester and Daunay, 2003; Maundu et al., 2009). Scarlet eggplant is, together with tomato, onion, pepper and okra, one of the five most important vegetables in Central and West Africa (Schippers, 2000; Maundu et al., 2009). Gboma eggplant is in general less important than scarlet eggplant, although in some areas like in Benin and in the rain forest regions of Coastal Africa and Congo River, is one of the major vegetables (Lester et al., 1990; Dansi et al., 2008). Cultivation of both species is mostly restricted to Africa, but S. aethiopicum is also cultivated in the Caribbean and Brazil (Schippers, 2000), where it was probably brought by slaves, as well as in some areas of the south of Italy (Sunseri et al., 2010).
Both scarlet and gboma eggplants are also important genetic resources for common eggplant (S. melongena L.) breeding, as the three species can be intercrossed giving hybrids with intermediate fertility (Daunay et al., 1991; Oyelana and Ugborogho, 2008; Prohens et al., 2012; Khan et al., 2013). Scarlet eggplant and its interspecific hybrids with S. melongena are also used as rootstocks for eggplant cultivation (Gisbert et al., 2011).

Within the genus Solanum, S. aethiopicum belongs to section Oliganthes (Lester, 1986; Lester and Niakan, 1986), while S. macrocarpon to section Melongena (Lester et al., 1990; Lester and Daunay, 2003; Lester et al., 2011). Solanum aethiopicum is a hypervariable species (i.e., characterized by many types and forms morphologically different), with hundreds of local varieties (Lester et al., 1986). Such morphological variability has resulted in about 20 different scientific names through the taxonomic history of this crop (Lester, 1986). Lester (1986) recognized four 


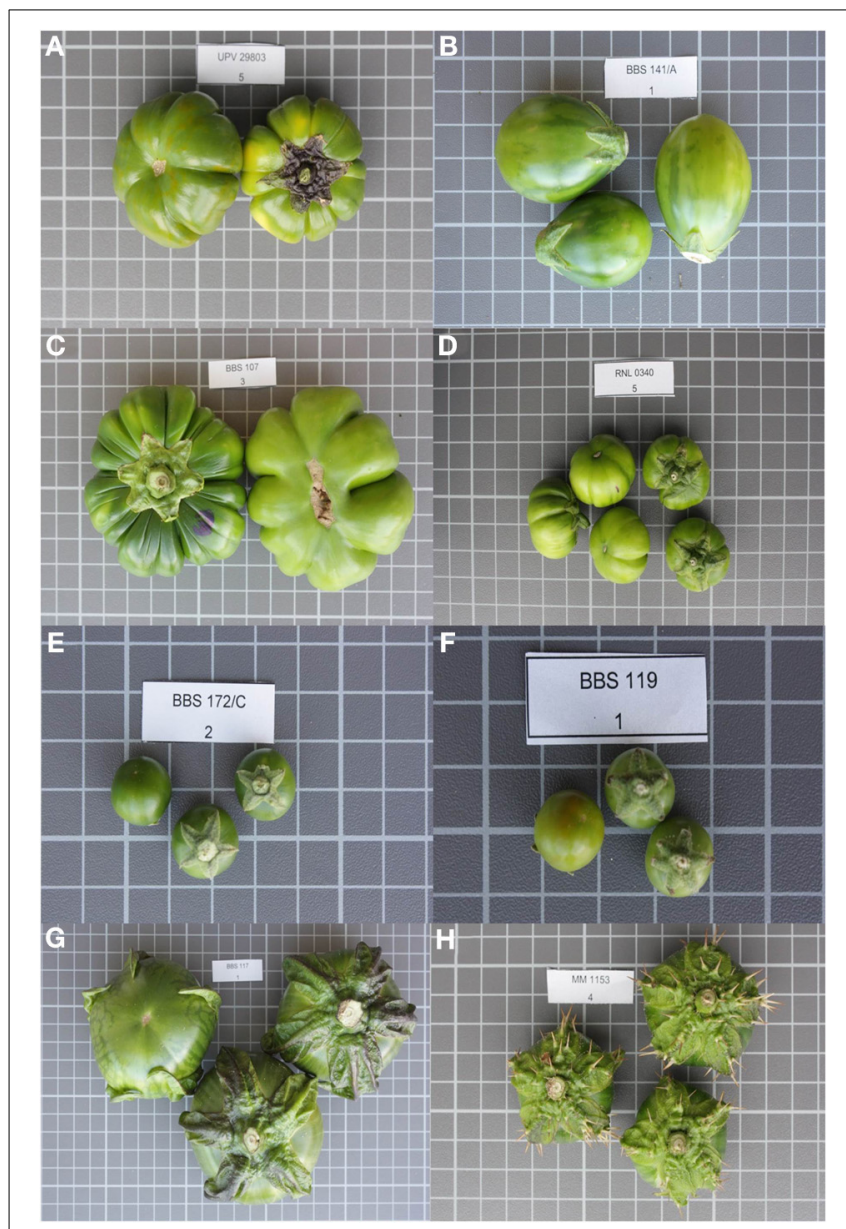

FIGURE 1 | Representative fruits of each of the scarlet eggplant complex ( $S$. aethiopicum and $S$. anguivi) and gboma eggplant complex (S. macrocarpon and $\boldsymbol{S}$. dasyphyllum) groups evaluated. Groups include S. aethiopicum groups Aculeatum (A), Gilo (B), Kumba (C), Shum (D), Intermediate beween $S$. aethiopicum and $S$. anguivi (E),

S. anguivi (F), S. macrocarpon (G), and $S$. dasyphyllum (H). Fruits are not depicted at the same scale; the size of the grid cells is $1 \times 1 \mathrm{~cm}$.

cultivar groups, namely Aculeatum, Gilo, Kumba, and Shum. The four cultivar groups of $S$. aethiopicum are completely interfertile (Lester and Niakan, 1986) and, although historically they have been treated as distinct species by several authors, it is generally accepted that they form part of a single species (Lester et al., 1986, 2011; Edmonds, 2012). Classification of accessions to their cultivar group can be made using a simple classification key (Lester et al., 1986). Regarding the utilization of each cultivar group, Aculeatum is used as an ornamental, Gilo for its fruits, Kumba for both fruits and leaves, and Shum for its leaves (Lester, 1986; Schippers, 2000; Lester and Daunay, 2003). The wild ancestor of S. aethiopicum is S. anguivi (Lester and Niakan, 1986). Hybrids between S. aethiopicum and S. anguivi Lam. are fully fertile (Lester and Niakan, 1986; Lester and Thitai, 1989). Solanum aethiopicum together with $S$. anguivi and their intermediate forms constitute the scarlet eggplant complex.

Solanum macrocarpon is also hypervariable in morphology, although to a lesser extent than S. aethiopicum (Lester and
Daunay, 2003). Depending on the cultivar, S. macrocarpon is cultivated for its fruits, leaves or both (Schippers, 2000; Lester and Daunay, 2003; Maundu et al., 2009). Solanum macrocarpon was domesticated from the wild S. dasyphyllum Schum and Thonn. (Bukenya and Carasco, 1994). Both species are fully interfertile and together with their weedy intermediate forms for the gboma eggplant complex (Bukenya and Carasco, 1994).

Morphological characterization using conventional descriptors has proved useful for describing and establishing relationships among cultivar groups and accessions in scarlet and gboma eggplants (Lester et al., 1986; Polignano et al., 2010; Sunseri et al., 2010; Adeniji et al., 2012, 2013). These works have mostly focused on scarlet eggplant, revealing that it is a highly variable crop. The most comprehensive study was performed by Lester et al. (1986) who characterized 108 accessions of the scarlet eggplant complex using morphological and taxonomically relevant traits and found that the four cultivar groups could be distinguished by a syndrome of characteristics (i.e., a set of characteristics that are observed in a single group). These authors also found some accessions which were intermediate between S. anguivi and S. aethiopicum (Lester et al., 1986). The rest of characterization works (Polignano et al., 2010; Sunseri et al., 2010; Adeniji et al., 2012, 2013) involved fewer accessions and were based on morphological and agronomic descriptors. These latter studies found some degree of differentiation among the four S. aethiopicum groups, but considerable overlapping among groups was found. Many fewer studies have been devoted to the diversity of gboma eggplant. Polignano et al. (2010) evaluated 16 accessions of $S$. macrocarpon and found that it was a variable crop, which presented a continuous variation for the morphological diversity.

Modern phenomics tools may also be useful for precise characterization and for studying the diversity and relationships in collections of genetic resources (Furbank and Tester, 2011). In this respect, the high-throughput phenomics software tool Tomato Analyzer, which was initially developed for fruit shape analysis in tomato (Brewer et al., 2006, 2007; Gonzalo and van der Knaap, 2008; Rodríguez et al., 2010), has also proved useful for the detailed and accurate characterization of eggplant accessions (Hurtado et al., 2013) as well as for segregating generations between $S$. melongena and S. aethiopicum (Prohens et al., 2012). Tomato Analyzer allows scoring a large number of fruit shape traits from scanned images of fruit sections and is a powerful tool for precise description of fruit morphology. Therefore, Tomato Analyzer may be useful for the fruit shape characterization of germplasm collections of scarlet and gboma eggplants. Furthermore, fruit shape is considered as a very important trait in the preferences of farmers in selecting a variety of scarlet or gboma eggplant (Adeniji and Aloyce, 2012) and in consequence is a trait of major importance in these two crops, especially in varieties used for their fruits.

In this work, we characterize a collection of accessions of the scarlet and gboma eggplants complexes using conventional and phenomics (Tomato Analyzer) descriptors. The objective is to provide phenotypic information of relevance on the diversity and relationships of the two crops and their cultivar groups. This 
Table 1 | Plant and fruit descriptors used for the characterization of a collection of scarlet eggplant complex (S. aethiopicum and $S$. anguivi) and gboma eggplant complex (S. macrocarpon and S. dasyphyllum) accessions.

\section{Descriptors \\ PLANT DESCRIPTORS}

Units/scale/description

Plant Height

Hypocotyl Anthocyanins

Intensity

Shoot Tip Anthocyanins

Intensity

Stem Diameter

Angle Between Main

Branches

Leaf Pedicel Length

Leaf Blade Length

Leaf Blade Breadth

Leaf Blade Lobing

Leaf Surface Shape

Leaf Prickles

Length of Largest Leaf

Prickle

Number of Flowers per

Inflorescence

Corolla Color

Number of Sepals

Number of Petals

Number of Stamens

Corolla Diameter

FRUIT DESCRIPTORS

Weight

Length

Breadth

Perimeter

Area

Width Mid-height

Maximum Width

Height Mid-width

Maximum Height

Fruit Shape Index External

Fruit Shape Index External II

Proximal Fruit Blockiness

Distal Fruit Blockiness

Fruit Shape Triangle

Ellipsoid $\mathrm{cm}$

(S) $0=$ Absent; 9 = Very strong

(S) $0=$ Absent; $9=$ Very strong

$\mathrm{cm}$

(S) $1 \leq 40^{\circ} ; 5>50^{\circ}$

$\mathrm{cm}$

$\mathrm{cm}$

$\mathrm{cm}$

(S) $1=$ Very weak; $9=$ Very strong

(S) $1=$ Flat; $9=$ Very convex or bullate

(S) $0=$ None; $9=$ Very many $(>20)$

$\mathrm{cm}$

(M)-

(S) $1=$ Greenish white; $9=$ Bluish

violet

(M)-

(M)-

(M)-

$\mathrm{mm}$

\section{g}

$\mathrm{cm}$

$\mathrm{cm}$

$\mathrm{cm}$

$\mathrm{cm}^{2}$

The width measured at $1 / 2$ of the fruit's height $(\mathrm{cm})$

The maximum horizontal distance of the fruit $(\mathrm{cm})$

The height measured at $1 / 2$ of the fruit's width $(\mathrm{cm})$

The maximum vertical distance of the fruit $(\mathrm{cm})$ Maximum Width

The ratio of the Height Mid-width to Width Mid-height

Ratio of the width at the upper blockiness position to Width_MH

Ratio of the width at the lower blockiness position to Width_MH Ratio of the width at the upper blockiness position to the lower blockiness position

The ratio of the error resulting from a best-fit ellipse to the area of the fruit; smaller values indicate that the fruit is more ellipsoid
The ratio of the Maximum Height to
Table 1 | Continued

Descriptors Units/scale/description

Circular

The ratio of the error resulting from a best-fit circle to the area of the fruit; smaller values indicate that the fruit is more circular

Rectangular

Shoulder Height

Distal End Protrusion

Obovoid

Ovoid

The ratio of the rectangle bounding the fruit to the rectangle bounded by the fruit

The ratio of the average height of the shoulder points above the proximal end point to Maximum Height

Ratio of the area of the distal protrusion to the total area of the fruit, multiplied by 10

Calculated according to the formula provided in the tomato Analyzer Manual (Rodríguez et al., 2010). The higher the value, the greater is the area of the fruit below mid height

Calculated according to the formula provided in the tomato Analyzer Manual (Rodríguez et al., 2010). The higher the value, the greater is the area of the fruit above mid height

Width Widest Pos

Eccentricity

Proximal Eccentricity

Distal Eccentricity

The ratio of the height at which the Max_Width occurs to the Max_Height The ratio of the height of the internal ellipse to the Maximum Height

The ratio of the area of the height of the internal ellipse to the distance between the bottom of the ellipse and the top of the fruit

The ratio of the area of the height of the internal ellipse to the distance between the bottom of the ellipse and the bottom of the fruit

Fruit Shape Index Internal The ratio of the internal ellipse's height to its width

Eccentricity Area Index

The ratio of the area of the fruit outside the ellipse to the total area of the fruit

Full details of the descriptors can be consulted elsewhere IIBPGR, 1990; Prohens et al., 2005; Brewer et al., 2006, 2007; van der Weerden and Barendse, 2007; Darrigues et al., 2008; Gonzalo and van der Knaap, 2008; Rodríguez et al., 2010). Thirty-four descriptors are metric, four are meristic, and seven are measured in a quantitative scale. The two latter are indicated by an " $M$ " and a " $Q$," respectively in their description.

information will be useful for the classification, management of genetic resources, selection and breeding of both crops.

\section{MATERIALS AND METHODS PLANT MATERIAL}

Sixty-three accessions of the scarlet eggplant complex (S. aethiopicum and S. anguivi) and 12 accessions of the gboma eggplant complex (S. macrocarpon and S. dasyphyllum) from the germplasm bank of the Universitat Politècnica de València (València, Spain) were used for the present study. The scarlet 


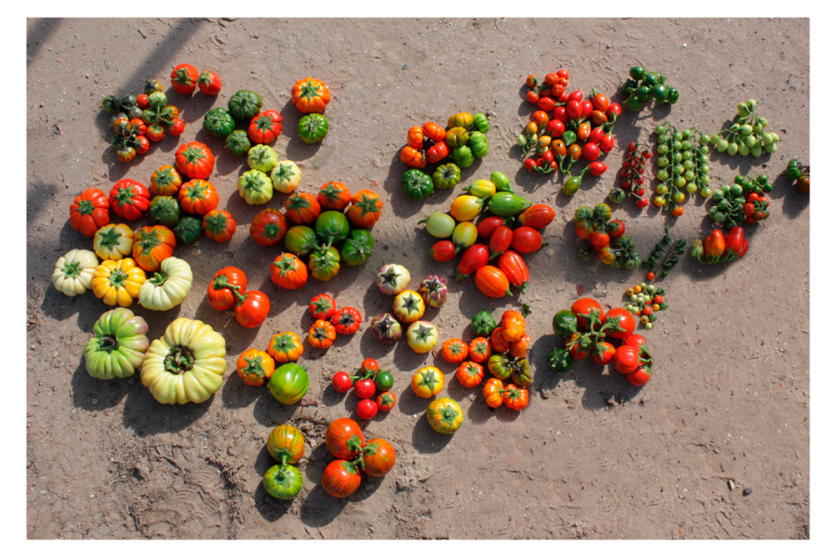

FIGURE 2 | Diversity among accessions of scarlet eggplant complex (S. aethiopicum and $\boldsymbol{S}$. anguivi) in the evaluated collection. Red fruits are physiologically mature.

eggplant complex accessions were classified according to the key to taxa of S. aethiopicum and S. anguivi established by Lester et al. (1986), which includes S. aethiopicum groups Aculeatum, Gilo, Kumba, and Shum, and S. anguivi (Figure 1). Accessions that could not be allocated to any of the groups, as they shared intermediate characteristics between S. aethiopicum and S. anguivi were assigned to a group denominated Intermediate. Gboma eggplant complex accessions were classified as S. macrocarpon or S. dasyphyllum according to the key of Lester et al. (2011) (Figure 1).

\section{CHARACTERIZATION}

Individual plants were characterized using 18 plant descriptors commonly used for cultivated eggplant species and wild relatives characterization (IBPGR, 1990; Prohens et al., 2005; van der Weerden and Barendse, 2007; Polignano et al., 2010; Prohens et al., 2012). Plant descriptors include traits related to whole plant (5), leaves (7), and inflorescences and flowers (6) (Table 1). Seven plant descriptors are metric, four are meristic (traits in which the number of parts or components are counted), and seven are measured in a quantitative scale. For each individual plant, several commercially ripe (i.e., physiologically immature, see Figure 1) fruits were weighted, manually measured for length and breadth, and longitudinally cut and scanned with an HP Scanjet G4010 photo scanner (HewlettPackard, Palo Alto, CA, USA) at a resolution of $300 \mathrm{dpi}$ and subjected to morphometric analysis with Tomato Analyzer version 3 software (Rodríguez et al., 2010). Data were recorded for a total of 27 fruit descriptors (Table 1), of which three were manually measured (Weight, Length, Breadth) and 24 were automatically obtained with Tomato Analyzer, including basic (6), fruit shape index (2), blockiness (3), homogeneity (3), proximal fruit end shape (1), distal fruit end shape (1), asymmetry (3), and internal eccentricity (5) descriptors. Nine fruit traits had units and 18 were unitless. All fruit descriptors were metric. Default settings were used for blockiness and proximal fruit end shape and distal fruit end shape descriptors (Rodríguez et al., 2010). A complete description of these traits can be found elsewhere

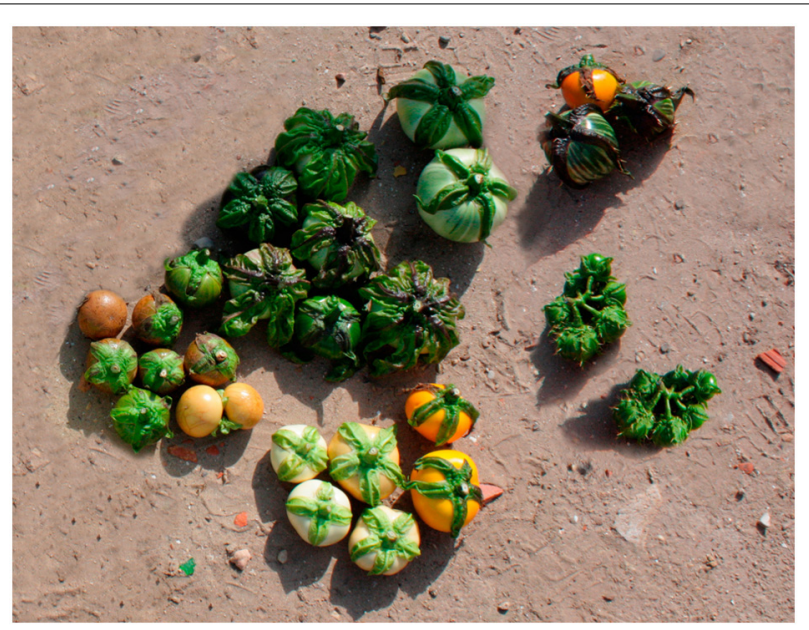

FIGURE 3 | Diversity among accessions of gboma eggplant complex (S. macrocarpon and $S$. dasyphyllum) eggplant in the evaluated collection. Yellow and brown fruits are physiologically mature.

(Rodríguez et al., 2010; Prohens et al., 2012; Hurtado et al., 2013).

\section{DATA ANALYSES}

The mean, range, and coefficient of variation $(\mathrm{CV})$ values for plant and fruit descriptors were calculated for each of the scarlet eggplant and gboma eggplant complexes. Two-tailed $t$ tests were performed on mean values for each descriptor in order to study signification of differences between means of scarlet and gboma eggplant complexes (Little and Hills, 1978). Analyses of variance (ANOVA) tests for each of the scarlet eggplant and gboma eggplant complexes were performed on plant and fruit values to detect differences among groups within each complex. For descriptors in which the mean was proportional to standard deviation, log transformed data were used for the ANOVA tests in order to avoid scaling effects (Little and Hills, 1978). Significant $(P<0.05)$ differences among group means were detected using the Student-Newman-Keuls multiple range test. No corrections were performed for controlling type I error (false positives) derived from multiple testing (Snedecor and Cochran, 1989). The number of significant differences between pairs of both scarlet eggplant and gboma eggplant groups means for plant and fruit descriptors were calculated. Principal components analysis (PCA) were performed using pairwise Euclidean distances among accession means.

\section{RESULTS}

\section{DIVERSITY AND DIFFERENCES BETWEEN SCARLET AND GBOMA EGGPLANT COMPLEXES}

The morphological characterization of scarlet and gboma eggplant complexes revealed that the collection studied was phenotypically very diverse (Figures 2,3 ). Both scarlet and gboma eggplant complexes displayed considerable diversity for most plant and fruit descriptors (Table 2). For plant traits measured in a scale, in both complexes the range of variation covers all or most 
Table 2 | Mean, range, and coefficient of variation (CV; \%) for the plant and fruit descriptors studied in the scarlet eggplant complex (S. aethiopicum and S. anguivi) and gboma eggplant complex (S. macrocarpon and $S$. dasyphyllum) accessions, and significance of the differences between complex means.

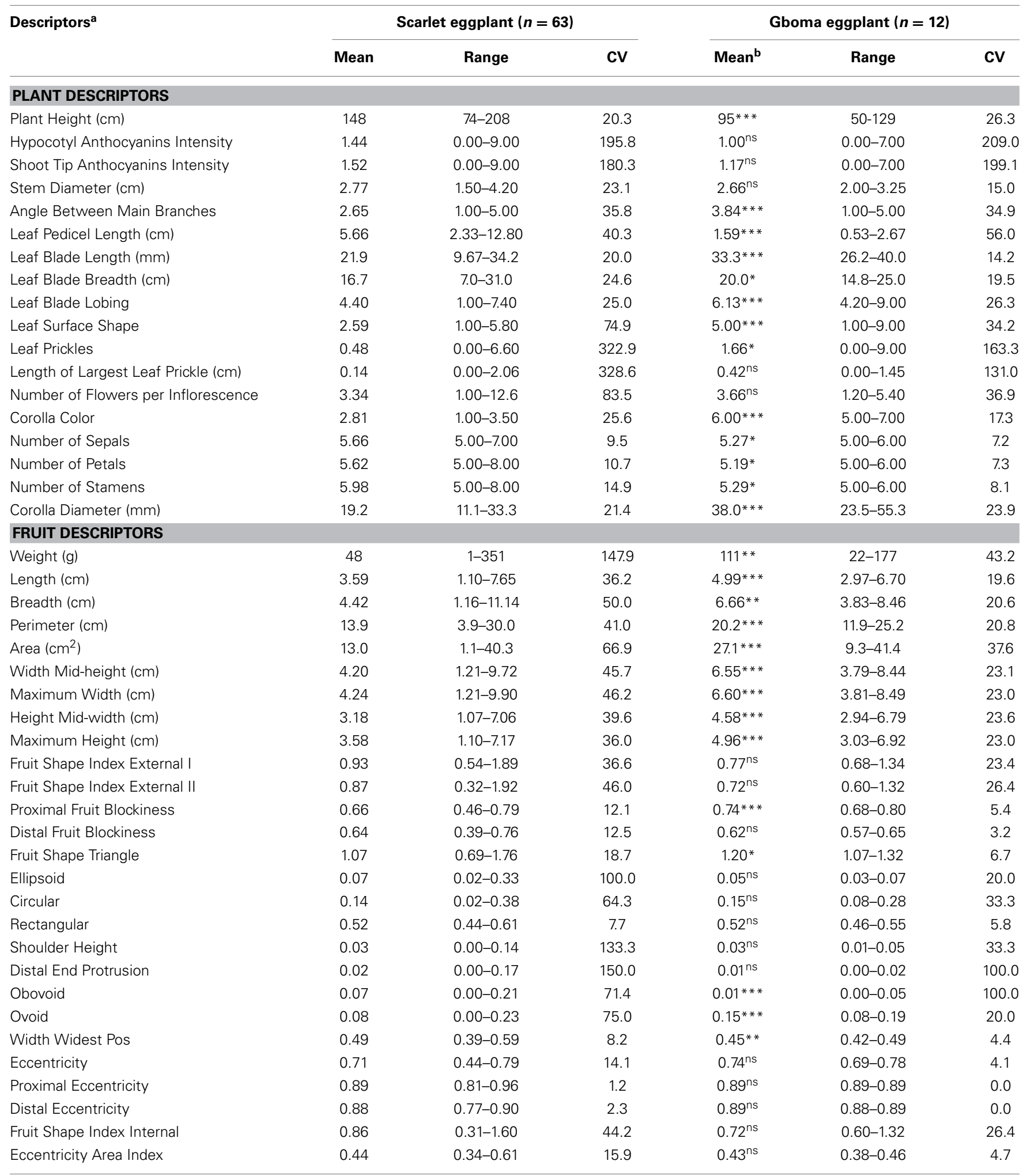

a See Table 1 for definition of descriptors.

$b^{* * *},{ }^{* *},{ }^{*}$, ns indicate, respectively, significant at $P<0.001, P<0.01, P<0.05$, or non-significant differences between scarlet and gboma eggplant complexes means, according to a two-tailed t-test. 
of the scale range, with the exception of Corolla Color, which in the scarlet eggplant complex presents low values of the scale, while in the gboma eggplant complex it presents intermediate-high values (Table 2). For the rest of plant traits, the range of variation was broad in both complexes. For both complexes, the largest values of CV were found for the two anthocyanin intensity and the two prickliness traits, with values always above $100 \%$ and up to $328.6 \%$ for Length of Largest Prickle in the scarlet eggplant complex (Table 2). Also, in both complexes the traits with lowest CV values were the Number of Sepals, Number of Petals, and Number of Stamens, with CV values always below 15\%. For 12 out of the 18 plant traits, the CV value was higher in the scarlet eggplant complex than in the gboma eggplant complex (Table 2).

As occurred for the plant descriptors, a wide diversity was found for most fruit traits within each of the scarlet and gboma eggplant complexes (Table 2). In particular, for the nine fruit size traits evaluated (Weight to Maximum Height) the ranges of variation were very large. For example Weight, ranged between 1 and $351 \mathrm{~g}$ in the scarlet eggplant complex and between 22 and $177 \mathrm{~g}$ in the gboma eggplant complex. For the unitless fruit shape traits in most cases an important variation was found in both complexes, although in some cases (e.g., Proximal Eccentricity and Distal Eccentricity in the gboma eggplant complex) the range of variation was very limited (Table 2 ). CV values of $100 \%$ or larger were found for Weight, Ellipsoid, Shoulder Height, and Distal End Protrusion in the scarlet group and for Distal End Protrusion and Obovoid for the gboma eggplant complex. In both complexes, the lowest CV values were found for Proximal Eccentricity and Distal Eccentricity, with values for both traits of $0.0 \%$ in the gboma eggplant complex and as low as 1.2 and $2.3 \%$, respectively, in the scarlet eggplant complex. For all fruit traits, with the exception of Obovoid, the CV was larger for the scarlet eggplant complex than for the gboma eggplant complex (Table 2).

Despite the wide diversity found within each of the scarlet eggplant and gboma eggplant complexes, many morphological significant $(P<0.05)$ differences existed for mean values between both complexes (Table 2 ). In this respect, when considering plant traits, on average, scarlet eggplants had plants that were taller (Plant Height), less erect (Angle Between Main Branches), with smaller leaf blade (Leaf Blade Length and Leaf Blade Breadth), less lobed leaves (Leaf Blade Loging), flatter leaf surface (Leaf Surface Shape), less prickly leaves (Leaf Prickles), greater number of flower parts (Number of Sepals, Number of Petals, and Number of Stamens), smaller flowers (Corolla Diameter), and longer leaf

Table 4 | Number of significant $(P<0.05)$ differences among means for scarlet eggplant complex groups $(S$. aethiopicum groups Aculeatum, Gilo, Kumba, and Shum, Intermediate between S. aethiopicum and S. anguivi, and $S$. anguivi) for 18 conventional descriptors (above the diagonal) and for 27 Tomato Analyzer descriptors (below the diagonal).

\begin{tabular}{|c|c|c|c|c|c|c|}
\hline & \multicolumn{4}{|c|}{ S. aethiopicum } & \multirow{2}{*}{$\begin{array}{c}\text { Inter- } \\
\text { mediate }\end{array}$} & \multirow[t]{2}{*}{ S. anguivi } \\
\hline & Aculeatum & Gilo & Kumba & Shum & & \\
\hline \multicolumn{7}{|c|}{ S. AETHIOPICUM } \\
\hline Aculeatum & & 5 & 5 & 8 & 4 & 5 \\
\hline Gilo & 8 & & 1 & 0 & 1 & 1 \\
\hline Kumba & 7 & 13 & & 5 & 4 & 7 \\
\hline Shum & 12 & 9 & 14 & & 1 & 2 \\
\hline Intermediate & 15 & 9 & 16 & 0 & & 0 \\
\hline S. anguivi & 14 & 14 & 20 & 3 & 6 & \\
\hline
\end{tabular}

Table 3 | Mean values for scarlet eggplant complex groups ( $S$. aethiopicum groups Aculeatum, Gilo, Kumba, and Shum, Intermediate between $S$. aethiopicum and $S$. anguivi, and $S$. anguivi) for the plant descriptors for which significant $(P<0.05)$ differences have been found among group means.

\begin{tabular}{|c|c|c|c|c|c|c|c|}
\hline \multirow[t]{2}{*}{ Descriptors } & \multicolumn{4}{|c|}{ S. aethiopicum } & \multirow[t]{2}{*}{ Intermediate } & \multirow[t]{2}{*}{ S. anguivi } & \multirow[t]{2}{*}{ Prob. F } \\
\hline & Aculeatum & Gilo & Kumba & Shum & & & \\
\hline$n$ & 5 & 37 & 10 & 2 & 8 & 1 & \\
\hline Plant Height (cm) & $151^{a b}$ & $156^{b}$ & $114^{a}$ & $135^{a b}$ & $153^{a b}$ & $150^{\mathrm{ab}}$ & 0.0033 \\
\hline Hypocotyl Anthocyanins Intensity & $7.80^{\mathrm{b}}$ & $0.31^{a}$ & $2.74^{\mathrm{a}}$ & $0.50^{a}$ & $1.49^{a}$ & $0.00^{a}$ & $<0.0001$ \\
\hline Shoot Tip Anthocyanins Intensity & $7.80^{\mathrm{b}}$ & $0.23^{a}$ & $2.98^{a}$ & $2.50^{a}$ & $1.68^{a}$ & $0.00^{a}$ & $<0.0001$ \\
\hline Angle Between Main Branches & $1.72^{a b}$ & $2.77^{a b}$ & $3.21^{b}$ & $2.00^{a b}$ & $2.35^{a b}$ & $1.00^{a}$ & 0.0134 \\
\hline Leaf Pedicel Length (cm) & $7.88^{b}$ & $5.23^{a b}$ & $6.74^{a b}$ & $3.47^{\mathrm{a}}$ & $5.82^{a b}$ & $3.00^{\mathrm{a}}$ & 0.0342 \\
\hline Leaf Blade Length (mm) & $23.8^{b c}$ & $21.5^{a b c}$ & $25.5^{c}$ & $14.3^{a}$ & $20.9^{a b c}$ & $15.5^{\mathrm{ab}}$ & 0.0031 \\
\hline Leaf Blade Breadth (cm) & $17.8^{a b}$ & $16.4^{\mathrm{ab}}$ & $19.5^{b}$ & $10.5^{\mathrm{a}}$ & $16.1^{a b}$ & $12.0^{\mathrm{ab}}$ & 0.0412 \\
\hline Leaf Surface Shape & $1.00^{a}$ & $2.54^{a b}$ & $3.88^{a b}$ & $4.33^{b}$ & $2.00^{a b}$ & $1.00^{a}$ & 0.0469 \\
\hline Leaf Prickles & $5.32^{b}$ & $0.00^{a}$ & $0.00^{a}$ & $0.00^{\mathrm{a}}$ & $0.47^{a}$ & $0.00^{\mathrm{a}}$ & $<0.0001$ \\
\hline Length of Largest Leaf Prickle (cm) & $1.62^{b}$ & $0.00^{\mathrm{a}}$ & $0.00^{\mathrm{a}}$ & $0.00^{\mathrm{a}}$ & $0.07^{a}$ & $0.00^{\mathrm{a}}$ & $<0.0001$ \\
\hline Number of Flowers per Inflorescence & $7.18^{\mathrm{b}}$ & $2.18^{a}$ & $1.97^{\mathrm{a}}$ & $3.33^{a}$ & $7.51^{\mathrm{b}}$ & $7.50^{\mathrm{b}}$ & $<0.0001$ \\
\hline Number of Sepals & $5.97^{a b}$ & $5.60^{a b}$ & $6.33^{b}$ & $5.27^{a}$ & $5.06^{a}$ & $5.00^{a}$ & $<0.0001$ \\
\hline Number of Petals & $5.92^{a b}$ & $5.50^{a b}$ & $6.39^{b}$ & $5.33^{\mathrm{ab}}$ & $5.16^{a}$ & $5.00^{a}$ & $<0.0001$ \\
\hline Number of Stamens & $6.01^{a b}$ & $5.91^{a b}$ & $7.18^{b}$ & $5.31^{a}$ & $5.06^{a}$ & $5.00^{a}$ & $<0.0001$ \\
\hline Corolla Diameter (mm) & $19.1^{a b}$ & $19.3^{a b}$ & $22.7^{b}$ & $12.5^{\mathrm{a}}$ & $16.8^{a b}$ & $13.2^{\mathrm{a}}$ & 0.0017 \\
\hline
\end{tabular}

${ }^{a}$ Means within rows separated by different letters are significantly different at $P<0.05$, according to the Student-Newman-Keuls test. 
Table 5 | Mean values for scarlet eggplant complex groups (S. aethiopicum groups Aculeatum, Gilo, Kumba, and Shum, Intermediate between S. aethiopicum and $S$. anguivi, and $S$. anguivi) for the fruit descriptors for which significant $(P<0.05)$ differences have been found among group means.

\begin{tabular}{|c|c|c|c|c|c|c|c|}
\hline Descriptors $^{a}$ & \multicolumn{4}{|c|}{ S. aethiopicum } & Intermediate & S. anguivi & Prob. F \\
\hline$n$ & 5 & 37 & 10 & 2 & 8 & 1 & \\
\hline Weight $(g)^{b}$ & $28.4^{c}$ & $32.4^{\mathrm{C}}$ & $166.6^{d}$ & $3.9^{b}$ & $4.8^{b}$ & $1.0^{\mathrm{a}}$ & $<0.0001$ \\
\hline Length $(\mathrm{cm})^{\mathrm{b}}$ & $2.62^{\mathrm{cd}}$ & $4.03^{d}$ & $4.21^{d}$ & $1.43^{\mathrm{ab}}$ & $2.20^{\mathrm{bc}}$ & $1.10^{\mathrm{a}}$ & $<0.0001$ \\
\hline Breadth $(\mathrm{cm})^{\mathrm{b}}$ & $4.63^{c}$ & $4.09^{c}$ & $8.22^{d}$ & $2.02^{b}$ & $2.06^{b}$ & $1.16^{\mathrm{a}}$ & $<0.0001$ \\
\hline Width Mid-height $(\mathrm{cm})^{b}$ & $4.59^{b}$ & $3.96^{b}$ & $7.41^{\mathrm{c}}$ & $1.97^{\mathrm{a}}$ & $2.00^{a}$ & $1.24^{\mathrm{a}}$ & $<0.0001$ \\
\hline Maximum Width $(\mathrm{cm})^{\mathrm{b}}$ & $4.61^{b}$ & $3.98^{\mathrm{b}}$ & $7.54^{c}$ & $1.98^{\mathrm{a}}$ & $2.02^{\mathrm{a}}$ & $1.25^{\mathrm{a}}$ & $<0.0001$ \\
\hline Height Mid-width $(\mathrm{cm})^{b}$ & $1.86^{\mathrm{ab}}$ & $3.82^{\mathrm{C}}$ & $2.92^{\mathrm{bc}}$ & $1.39^{a}$ & $2.03^{\mathrm{ab}}$ & $1.15^{\mathrm{a}}$ & $<0.0001$ \\
\hline Maximum Height $(\mathrm{cm})^{b}$ & $2.71^{\mathrm{cd}}$ & $4.00^{d}$ & $4.32^{d}$ & $1.48^{\mathrm{ab}}$ & $2.07^{b c}$ & $1.17^{\mathrm{a}}$ & $<0.0001$ \\
\hline Fruit Shape Index External I & $0.59^{a}$ & $1.06^{b}$ & $0.57^{a}$ & $0.76^{\mathrm{ab}}$ & $1.04^{b}$ & $0.93^{\mathrm{ab}}$ & $<0.0001$ \\
\hline Ellipsoid ${ }^{b}$ & $0.09^{a}$ & $0.04^{a}$ & $0.18^{b}$ & $0.04^{a}$ & $0.04^{a}$ & $0.02^{\mathrm{a}}$ & $<0.0001$ \\
\hline Circularb & $0.29^{b}$ & $0.10^{\mathrm{a}}$ & $0.25^{b}$ & $0.10^{\mathrm{a}}$ & $0.08^{a}$ & $0.02^{\mathrm{a}}$ & $<0.0001$ \\
\hline Rectangular & $0.57^{b}$ & $0.51^{\mathrm{ab}}$ & $0.54^{a b}$ & $0.50^{\mathrm{ab}}$ & $0.48^{a}$ & $0.50^{\mathrm{ab}}$ & 0.0007 \\
\hline Shoulder Height ${ }^{b}$ & $0.11^{b}$ & $0.02^{\mathrm{a}}$ & $0.08^{b}$ & $0.02^{\mathrm{a}}$ & $0.01^{a}$ & $0.00^{\mathrm{a}}$ & $<0.0001$ \\
\hline Obovoid & $0.05^{\mathrm{ab}}$ & $0.08^{\mathrm{ab}}$ & $0.03^{a}$ & $0.03^{\mathrm{a}}$ & $0.07^{a b}$ & $0.13^{b}$ & 0.0073 \\
\hline Ovoid & $0.08^{\mathrm{ab}}$ & $0.06^{\mathrm{ab}}$ & $0.16^{b}$ & $0.10^{\mathrm{ab}}$ & $0.08^{a b}$ & $0.01^{a}$ & $<0.0001$ \\
\hline Width Widest Pos & $0.47^{a b}$ & $0.50^{\mathrm{b}}$ & $0.43^{a}$ & $0.46^{\mathrm{ab}}$ & $0.49^{a b}$ & $0.49^{b}$ & $<0.0001$ \\
\hline Eccentricity & $0.55^{a}$ & $0.75^{\mathrm{b}}$ & $0.55^{a}$ & $0.76^{\mathrm{b}}$ & $0.78^{b}$ & $0.78^{b}$ & $<0.0001$ \\
\hline Fruit Shape Index Internal & $0.41^{a}$ & $1.02^{\mathrm{b}}$ & $0.41^{\mathrm{a}}$ & $0.72^{\mathrm{ab}}$ & $1.03^{b}$ & $0.92^{\mathrm{b}}$ & $<0.0001$ \\
\hline Eccentricity Area Index & $0.56^{b}$ & $0.41^{a}$ & $0.54^{b}$ & $0.42^{\mathrm{a}}$ & $0.39^{a}$ & $0.39^{a}$ & $<0.0001$ \\
\hline
\end{tabular}

a Means within rows separated by different letters are significantly different at $P<0.05$, according to the Student-Newman-Keuls test.

$\mathrm{b}$ In order to avoid scaling effects caused by accession means being proportional to standard deviations, ANOVAs were performed on log transformed data.

pedicel (Leaf Pedicel Length) than gboma eggplants (Table 2). Regarding fruit traits, the scarlet eggplant complex fruits were, on average, smaller (lower values for the nine fruit size traits), less blocky in the proximal part (Proximal Fruit Blockiness), less triangular (Fruit Shape Triangle), more obovoid (and less ovoid), and with highest values for the ratio of the height at which the maximum width occurs (Width Widest Pos) than the gboma eggplant complex fruits (Table 2).

\section{DIFFERENCES AND RELATIONSHIPS AMONG SCARLET EGGPLANT GROUPS}

Significant $(P<0.05)$ differences were found among the six scarlet eggplant complex groups for 15 out of the 18 plant traits evaluated (Table 3). The only exceptions were Stem Diameter, Leaf Blade Lobing, and Corolla Color. The number of significant differences between means of the scarlet eggplant complex groups for the 18 plant morphological traits evaluated range from 0 (between Gilo and Shum on one side and Intermediate and S. anguivi on the other) and 8 (between Aculeatum and Shum) (Table 4). Few differences in plant traits were also found between group Gilo on one side and groups Kumba, Intermediate and $S$. anguivi on the other, as well as between groups Shum, Intermediate and S. anguivi (Table 4). Among the most relevant differences found among scarlet eggplant complex groups for plant traits average values, plants of group Gilo were taller than those of group Kumba, group Aculeatum had higher anthocyanin content and prickliness than the other groups, groups Aculeatum, Intermediate and S. anguivi had more flowers per inflorescence than groups Gilo, Kumba, and Shum, group Kumba had larger flowers and higher number of flower parts than groups Shum, Intermediate and S. anguivi, and larger leaves than groups Shum and S. anguivi (Table 3 ).

For fruit traits, significant $(P<0.05)$ differences were found among the six scarlet eggplant complex groups for 24 out of the 27 fruit traits evaluated (Table 5). The number of significant differences among groups for fruit traits ranged from zero (between groups Shum and Intermediate) to 20 (between groups Kumba and S. anguivi) (Table 4). As occurred for plant traits, groups Shum, Intermediate and S. anguivi presented few differences (between 0 and 6). The rest of pairwise comparisons between groups presented at least 7 differences (Table 4). For the nine fruit size traits, in general the Kumba group presented 
Table 6 | Correlation coefficients between plant and fruit descriptors and the two first principal components the for scarlet eggplant complex (S. aethiopicum and $S$. anguivi).

\begin{tabular}{|c|c|c|}
\hline Descriptor & $\begin{array}{c}\text { First principal } \\
\text { component }\end{array}$ & $\begin{array}{l}\text { Second principal } \\
\text { component }\end{array}$ \\
\hline \multicolumn{3}{|l|}{ PLANT DESCRIPTORS } \\
\hline Hypocotyl Anthocyanins Intensity & & 0.198 \\
\hline Shoot Tip Anthocyanins Intensity & & 0.218 \\
\hline Angle Between Main Branches & & -0.160 \\
\hline Leaf Prickles & & 0.230 \\
\hline Length of Largest Leaf Prickle & & 0.230 \\
\hline Number of Flowers per Inflorescence & & 0.233 \\
\hline Number of Sepals & -0.193 & \\
\hline Number of Petals & -0.206 & \\
\hline Number of Stamens & -0.203 & \\
\hline \multicolumn{3}{|l|}{ FRUIT DESCRIPTORS } \\
\hline Weight & -0.194 & \\
\hline Length & & -0.312 \\
\hline Breadth & -0.231 & \\
\hline Perimeter & -0.205 & -0.191 \\
\hline Area & -0.186 & -0.218 \\
\hline Width Mid-height & -0.232 & \\
\hline Maximum Width & -0.233 & \\
\hline Height Mid-width & & -0.315 \\
\hline Maximum Height & & -0.309 \\
\hline Fruit Shape Index External I & 0.182 & -0.185 \\
\hline Fruit Shape Index External II & 0.197 & -0.177 \\
\hline Proximal Fruit Blockiness & -0.160 & \\
\hline Distal Fruit Blockiness & & 0.167 \\
\hline Ellipsoid & -0.197 & \\
\hline Circular & -0.200 & \\
\hline Shoulder Height & -0.195 & \\
\hline Ovoid & -0.172 & \\
\hline Width Widest Pos & 0.169 & \\
\hline Eccentricity & 0.233 & \\
\hline Fruit Shape Index Internal & 0.202 & -0.178 \\
\hline Eccentricity Area Index & -0.231 & \\
\hline Variance Explained (\%) & 33.7 & 16.6 \\
\hline
\end{tabular}

Only those correlations with absolute values $\geq 0.15$ have been listed.

the largest values, followed by groups Aculeatum and Gilo, then the groups Shum and Intermediate, and finally by $S$. anguivi, which presented the smallest fruits (Table 5). When considering fruit shape traits, the most relevant differences were that groups Aculeatum and Kumba had fruits more flattened (Fruit shape Index External I and II) than groups Gilo and Intermediate, group Aculeatum presented higher values for Proximal Fruit Blockiness than S. anguivi and of Distal Fruit Blockiness than groups Kumba and Intermediate, group Kumba was characterized by higher values of Triangular than S. anguivi and was less ellipsoid (i.e., higher Ellipsoid values) than the rest of groups, groups Aculeatum and Kumba were less circular (i.e., higher Circular values), had higher Shouder Height, Eccentricity, Fruit Shape Index Internal and Eccentricity Area Index than the rest of groups, and S. anguivi was more Obovoid than groups Kumba and Shum (Table 5).
The first and second components of the PCA accounted, respectively, for 33.7 and $16.6 \%$ of the total variation among accession means (Table 6). The first component was positively correlated to elongated fruits (Fruit Shape Index External I and II, and Fruit Shape Index Internal), Width Widest Pos, and Eccentricity and negatively to number of flower parts (sepals, petals, stamens), fruit size (except for the fruit length traits), and fruits less ellipsoid and circular (i.e., higher Ellipsoid and Circular values), and with high values for Shoulder Height, Ovoid, and Eccentricity Area Index (Table 6). The second component was positively correlated with anthocyanin intensity traits, prickliness traits, Number of Flowers per Inflorescence, and Distal Fruit Blockiness and negatively with Angle between Main Branches and with traits related to elongated (Length, Height Mid-width, Maximum Height, Fruit Shape Index External I and II, and Fruit Shape Internal) and large fruits (Perimeter and Area) (Table 6).

The projection of the accessions on a two-dimensional PCA plot showed that accessions of the different scarlet eggplant complex groups plotted in different areas of the graph, although the Intermediate group overlapped with several of the other groups (Figure 4). The Aculeatum group had a low dispersion and all accessions presented negative values for the first component and highly positive values for the second component. The Gilo group presented the largest dispersion; however, despite this wide dispersion it overlapped only with some accessions of the Intermediate group. Kumba group accessions presented intermediate values for the first component and high negative values for the second component and display an intermediate level of dispersion compared to Aculateum and Gilo groups in the PCA graph. The small fruited Shum, Intermediate and $S$. anguivi groups presented a combination of high values for the first component (in particular S. anguivi) with moderate, generally positive, values for the second component. The Shum group and $S$. anguivi were separated from each other and from the Gilo group, but the Intermediate group overlapped with part of the areas where the Shum group accessions and small fruited accessions of the Gilo group plot and is also situated in the area intermediate between S. anguivi, Shum, and Gilo groups (Figure 4).

\section{DIFFERENCES AND RELATIONSHIPS AMONG GBOMA EGGPLANT GROUPS}

Significant $(P<0.05)$ differences between $S$. macrocarpon and $S$. dasyphyllum were found only for three morphological traits (Table 7). In this respect, S. macrocarpon presented significantly less bullate leaves (Leaf Surface Shape) and lower prickliness (Leaf Prickless and Length of Largest Leaf Prickle) than S. dasyphyllum. Regarding fruit traits, significant differences between the two gboma eggplant groups were found for eleven traits. Solanum macrocarpon fruits presented significantly larger fruits (higher values for seven out of the eight fruit size traits, the exception being Height Mid-width), more ovoid (lower values for Obovoid and higher for Ovoid), and with lowest values for the ratio of the height at which the maximum width occurs (Width Widest Pos) than those of S. dasyphyllum (Table 7).

The first and second components of the PCA accounted, respectively, for 31.3 and $22.5 \%$ of the total variation among 


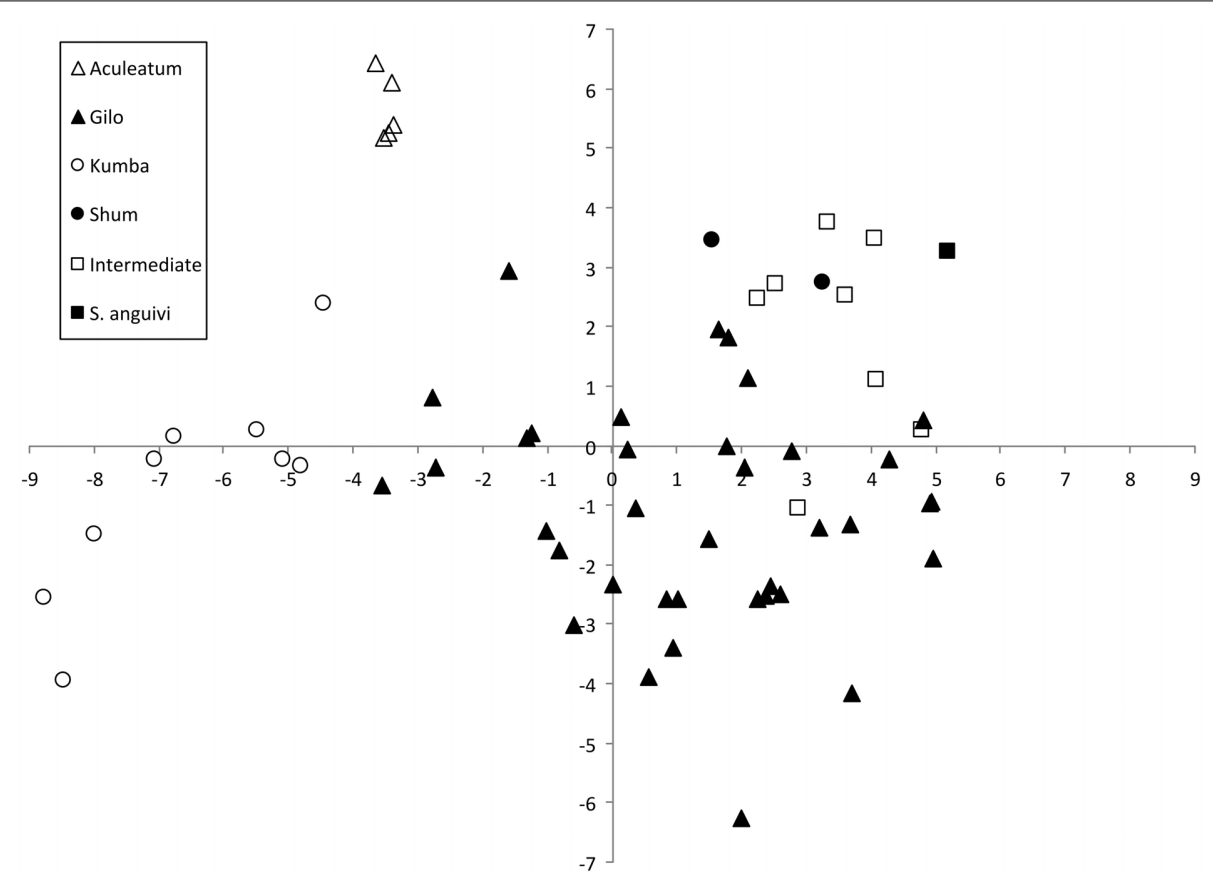

FIGURE 4 | Similarities based on 18 plant and 27 fruit descriptors among 63 scarlet eggplant complex ( $S$. aethiopicum and $S$. anguivi) accessions represented on the two first principal components of PCA. First and second components account for 33.7 and $16.6 \%$ of the total variation, respectively. The six groups considered are represented by different symbols: S. aethiopicum groups Aculeatum (open triangle), Gilo (filled triangle), Kumba (open circle), and Shum (filled circle); Intermediate between S. aethiopicum and S. anguivi (open square); and, S. anguivi (filled square). accession means (Table 8). The first component was positively correlated to prickliness (Leaf Prickles), elongated fruits (Fruit Shape Index External II), Width Widest Pos, and Eccentricity, and negatively to number of flower parts (Number of Petals, Number of Stamens), Corolla Diameter, leaf blade size, fruit size (except for the fruit length traits), and fruits more triangular, less ellipsoid and circular (i.e., higher Ellipsoid and Circular values), and with high values for Ovoid, and Eccentricity Area Index (Table 8). The second component was positively correlated with Plant Height, Stem Diameter, Number of Flowers per Inflorescence, Distal Fruit Blockiness and Proximal Eccentricity and negatively with anthocyanins intensity, traits related to elongated (Length, Height Mid-width, Maximum Height, Fruit Shape Index External I and II) and large fruits (Perimeter and Area) (Table 8).

The projection of the accessions on a two-dimensional PCA plot clearly shows that accessions of S. macrocarpon and S. dasyphyllum groups plot in different areas of the graph (Figure 5). The single accession of $S$. dasyphyllum presents the highest values for the first and second components. With the exception of one odd accession, all the $S$. macrocarpon accessions present intermediate values for the first component. The odd $S$. macrocarpon accession, with an extremely low value for the second component is distinct from the others in having elongated fruit shape.

\section{DISCUSSION}

Scarlet and gboma eggplants are important vegetables in tropical sub-Saharan Africa but have received little attention from the formal breeding sector (Lester and Thitai, 1989; Schippers, 2000; Seck, 2000; Adeniji and Aloyce, 2012; Prohens et al., 2012). This has allowed the on-site conservation of a large number of local varieties which, together with accessions conserved in germplasm banks, represent genetic resources for the enhancement of both crops (Lester et al., 1990; Bukenya and Carasco, 1994; Schippers, 2000; Sekara et al., 2007). The detailed morphological characterization of germplasm collections will allow studying the diversity and identification of potentially interesting accessions for selection and breeding, as well as devising strategies for conservation and management of germplasm (Furbank and Tester, 2011). Also, given that both crops and their wild relatives form part of the secondary genepool of common eggplant, information on the phenotypic diversity of scarlet and gboma eggplants may be of interest for common eggplant breeding (Daunay et al., 1991; Oyelana and Ugborogho, 2008; Prohens et al., 2012; Khan et al., 2013).

Morphological characterization is essential for the identification of valuable germplasm accessions as well as for typification and classification of accessions in cultivar groups (Spooner et al., 2003). Characterization of cultivated eggplants and wild relatives has usually been performed with conventional morphological descriptors highly heritable and simple to evaluate (IBPGR, 1990; Prohens et al., 2005; van der Weerden and Barendse, 2007; Polignano et al., 2010; Prohens et al., 2012). These descriptors are very useful but have some limitations especially for fruit shape characterization, which is one of the most important traits in a variety of any of the cultivated eggplant species and for which great diversity exists (Adeniji and Aloyce, 2012; Hurtado et al., 2013). Here we have complemented a standard morphological characterization with a fruit shape phenomics characterization 
Table 7 | Mean values for gboma eggplant complex groups (S. macrocarpon and $S$. dasyphyllum) for the plant and fruit descriptors for which significant $(P<0.05)$ differences have been found among group means.

\begin{tabular}{|c|c|c|c|}
\hline \multirow[t]{2}{*}{ Descriptors $^{a}$} & \multicolumn{2}{|c|}{ Gboma eggplant } & \multirow[t]{2}{*}{ Prob. F } \\
\hline & S. macrocarpon & S. dasyphyllum & \\
\hline$n$ & 11 & 1 & \\
\hline Leaf Surface Shape & $4.64^{a}$ & $9.00^{\mathrm{b}}$ & 0.0061 \\
\hline Leaf Prickles & $0.99^{a}$ & $9.00^{b}$ & 0.0004 \\
\hline $\begin{array}{l}\text { Length of Largest Leaf } \\
\text { Prickle }(\mathrm{cm})\end{array}$ & $0.33^{a}$ & $1.45^{\mathrm{b}}$ & 0.0442 \\
\hline Weight $(g)^{b}$ & $119.1^{b}$ & $21.9^{a}$ & 0.0026 \\
\hline Length $(\mathrm{cm})^{b}$ & $5.18^{\mathrm{b}}$ & $2.97^{a}$ & 0.0068 \\
\hline Breadth $(\mathrm{cm})^{\mathrm{b}}$ & $6.92^{\mathrm{b}}$ & $3.83^{a}$ & 0.0075 \\
\hline Perimeter $(\mathrm{cm})^{\mathrm{b}}$ & $21.0^{\mathrm{b}}$ & $11.9^{\mathrm{a}}$ & 0.0136 \\
\hline Area $\left(\mathrm{cm}^{2}\right)^{\mathrm{b}}$ & $28.8^{\mathrm{b}}$ & $9.3^{\mathrm{a}}$ & 0.0140 \\
\hline Width Mid-height $(\mathrm{cm})^{b}$ & $6.80^{\mathrm{b}}$ & $3.79^{a}$ & 0.0206 \\
\hline Maximum Width $(\mathrm{cm})^{\mathrm{b}}$ & $6.85^{\mathrm{b}}$ & $3.81^{\mathrm{a}}$ & 0.0199 \\
\hline Maximum Width $(\mathrm{cm})^{\mathrm{b}}$ & $5.14^{b}$ & $3.03^{\mathrm{a}}$ & 0.0371 \\
\hline Obovoid & $0.01^{a}$ & $0.05^{b}$ & 0.0093 \\
\hline Ovoid & $0.16^{b}$ & $0.08^{a}$ & 0.0064 \\
\hline Width Widest Pos & $0.44^{\mathrm{a}}$ & $0.49^{b}$ & 0.0488 \\
\hline
\end{tabular}

${ }^{a}$ Means within rows separated by different letters are significantly different at $P<0.05$, according to the Student-Newman-Keuls test.

${ }^{b}$ In order to avoid scaling effects caused by accession means being proportional to standard deviations, ANOVAs were performed on log transformed data.

using the high-throughput phenomics Tomato Analyzer (Brewer et al., 2006, 2007; Gonzalo and van der Knaap, 2008; Rodríguez et al., 2010), which has allowed the automated acquisition of multiple data of different fruit shape characteristics in both scarlet and gboma eggplants complexes. Combination of both types of data has allowed identification of multiple traits which distinguish clearly not only both crops and the cultivated species from the wild relatives, but also cultivar groups, which is not always possible using conventional descriptors (Polignano et al., 2010; Adeniji et al., 2012, 2013), as well as to describe the diversity present for traits of interest for selecting and developing improved materials in both crops. Descriptors presenting highly significant differences among groups and which plot in different parts of the PCA graph (i.e., descriptors that do not present high correlation values) would be the most informative for distinguishing between cultivar groups.

Scarlet and gboma eggplants are classified in different botanical sections within Solanum subgenus Leptostemonun (Lester, 1986; Lester and Daunay, 2003; Lester et al., 2011; Edmonds, 2012). Our results confirm that the scarlet and gboma eggplant complexes differ in many morphological differences, both for plant and fruit traits of agronomic interest. Polignano et al. (2010) also found that the cultivated S. aethiopicum and S. macrocarpon presented considerable differences for agronomic descriptors. Although some differences considered as significant $(P<0.05)$ might have resulted from false positives derived from multiple testing (Snedecor and Cochran, 1989), most of them have been
Table 8 | Correlation coefficients between plant and fruit descriptors and the two first principal components for the gboma eggplant complex (S. macrocarpon and $S$. dasyphyllum).

\begin{tabular}{|c|c|c|}
\hline Descriptor & $\begin{array}{l}\text { First principal } \\
\text { component }\end{array}$ & $\begin{array}{l}\text { Second principal } \\
\text { component }\end{array}$ \\
\hline \multicolumn{3}{|l|}{ PLANT DESCRIPTORS } \\
\hline Plant Height & & 0.219 \\
\hline Hypocotyl Anthocyanins Intensity & & -0.266 \\
\hline Shoot Tip Anthocyanins Intensity & & -0.247 \\
\hline Stem Diameter & & 0.206 \\
\hline Leaf Blade Length & -0.212 & \\
\hline Leaf Blade Breadth & -0.156 & \\
\hline Leaf Prickles & 0.150 & \\
\hline Number of Flowers per Inflorescence & & 0.207 \\
\hline Number of Petals & -0.172 & \\
\hline Number of Stamens & -0.161 & \\
\hline Corolla Diameter & -0.217 & \\
\hline \multicolumn{3}{|l|}{ FRUIT DESCRIPTORS } \\
\hline Weight & -0.216 & \\
\hline Length & & -0.265 \\
\hline Breadth & -0.243 & \\
\hline Perimeter & -0.212 & -0.154 \\
\hline Area & -0.201 & -0.154 \\
\hline Width Mid-height & -0.238 & \\
\hline Maximum Width & -0.239 & \\
\hline Height Mid-width & & -0.288 \\
\hline Maximum Height & & -0.271 \\
\hline Fruit Shape Index External I & & -0.255 \\
\hline Fruit Shape Index External II & 0.152 & -0.245 \\
\hline \multicolumn{3}{|l|}{ Proximal Fruit Blockiness } \\
\hline Distal Fruit Blockiness & & 0.245 \\
\hline Fruit Shape Triangle & -0.154 & \\
\hline Ellipsoid & -0.169 & \\
\hline Circular & -0.168 & \\
\hline Ovoid & -0.197 & \\
\hline Width Widest Pos & 0.224 & \\
\hline Eccentricity & 0.230 & \\
\hline Proximal Eccentricity & & 0.194 \\
\hline Fruit Shape Index Internal & 0.152 & \\
\hline Eccentricity Area Index & -0.220 & \\
\hline Variance Explained (\%) & 31.3 & 22.5 \\
\hline
\end{tabular}

Only those correlations with absolute values $\geq 0.15$ have been listed.

highly significant $(P<0.001)$, indicating that even with highly stringent tests they would have been significant, revealing that very likely they correspond to real differences. This differentiation is also confirmed at the molecular and chemical composition levels (Furini and Wunder, 2004; Polignano et al., 2010; SánchezMata et al., 2010; Vorontsova et al., 2013). Given that both crops can be intercrossed and hybrids have intermediate fertility (Daunay et al., 1991; Oyelana and Ugborogho, 2008), scarlet and gboma eggplants could be used for reciprocal breeding in order to introgress traits of interest from one species into the other (Prohens et al., 2012). 


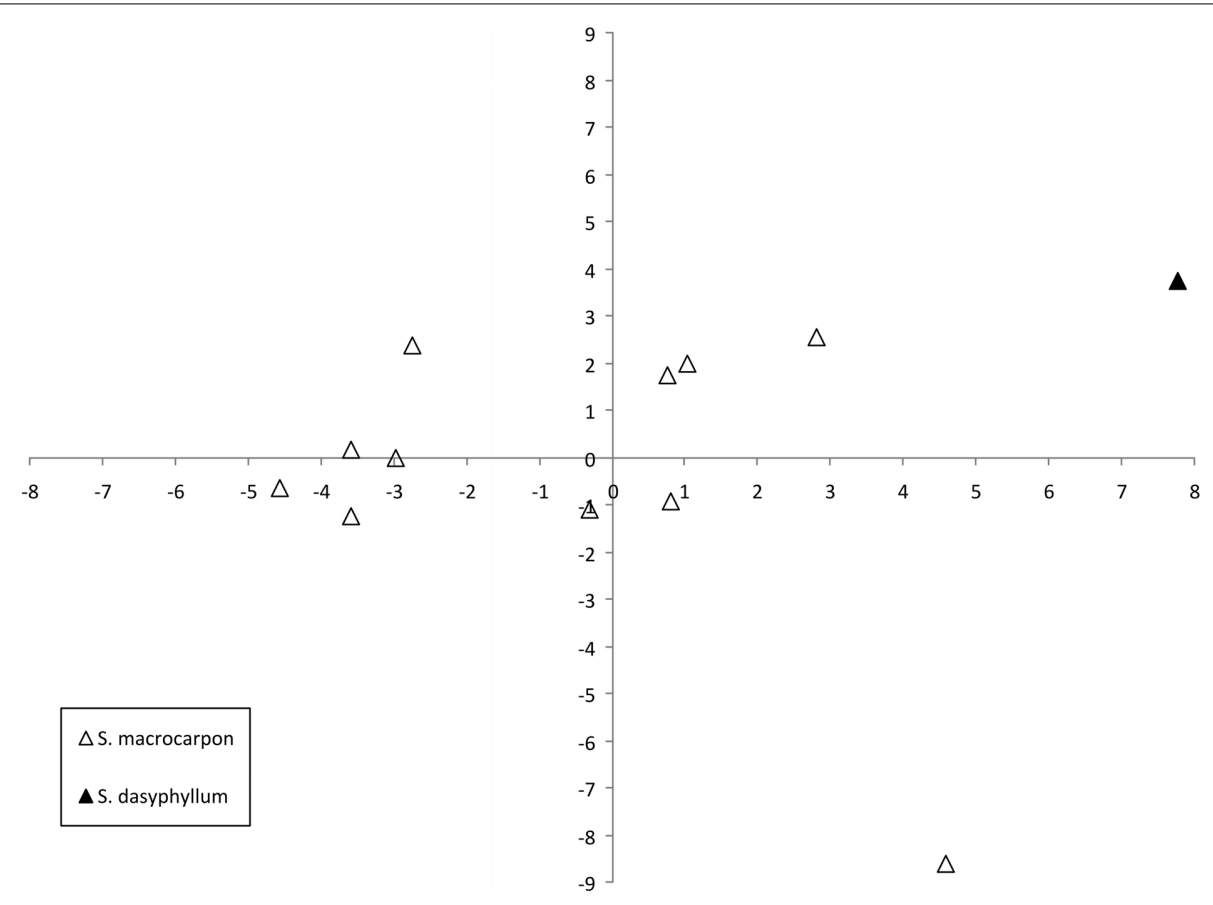

FIGURE 5 | Similarities based on 18 plant and 27 fruit descriptors among 12 gboma eggplant complex ( $S$. aethiopicum and $S$. anguivi) accessions represented on the two first principal components of PCA. First and second components account for 31.3 and $22.5 \%$ of the total variation, respectively. The two species are represented by different symbols: S. macrocarpon (open triangle), and S. dasyphyllum (filled triangle).
We have found a large diversity in both scarlet and gboma eggplants complexes for plant and fruit traits, with wide ranges of variations for most descriptors, confirming that they are hypervariable (Lester and Niakan, 1986; Lester et al., 1986; Bukenya and Carasco, 1994; Schippers, 2000). The variation of Solanum aethiopicum is so high that the different cultivar groups have, in the past, been considered as different species (Lester, 1986; Lester et al., 1986, 2011). Our combined study of conventional and Tomato Analyzer descriptors, together with multivariate PCA results, shows that each of the $S$. aethiopicum cultivar groups as well as $S$. anguivi are distinguished by many traits, which supports Lester (1986) view that each of the S. aethiopicum cultivar groups and the wild ancestor $S$. anguivi are characterized by a specific syndrome of characteristics. As expected, the wild S. anguivi, the intermediate forms between S. aethiopicum and $S$. anguivi, as well as the $S$. aethiopicum Shum group, which is only used for the leaves, have small fruits (Lester and Niakan, 1986; Lester et al., 1986, 1990; Schippers, 2000). Also, the gboma eggplant complex has proved to be highly diverse (Bukenya and Carasco, 1994; Lester et al., 1990; Polignano et al., 2010). Apart from leaf surface shape and prickliness, the differences observed between S. macrocarpon and S. dasyphyllum correspond to fruit traits evaluated with Tomato Analyzer. Most of the traits for which differences have been found among scarlet eggplant complex groups (including S. anguivi) as well as between S. macrocarpon and S. dasyphyllum correspond to fruit shape traits identified using the Tomato Analyzer tool, showing the potential of this phenomics tool for fruit shape characterization in eggplants (Prohens et al., 2012; Hurtado et al., 2013). In fact, while no significant differences were found for conventional plant descriptors between S. aethiopicum Gilo and Shum groups on one hand, as well as between the Intermediate group and S. anguivi on the other, the Tomato Analyzer characterization of fruit shape has allowed the detection of significant differences for fruit shape traits among them.

Apart from the differences among S. aethiopicum groups, a wide diversity has been found within each of them, as well as within S. macrocarpon. Within S. aethiopicum, the largest diversity has been found in the Gilo group, which is in agreement with previous observations and also with the fact that it is the most spread and important cultivar group (Lester et al., 1986, 1990; Schippers, 2000; Polignano et al., 2010; Sunseri et al., 2010). The Kumba group has been found to be less diverse that the Gilo group. The fact that the characteristic highly furrowed and flattened fruits of the Kumba group may be the result of a mutation similar to that of the tomato FASCIATED mutation, which is responsible for a high degree of fasciation in this crop (Monforte et al., 2014), may account for the lower degree of diversity compared to the Gilo group (Lester et al., 1986). Amazingly, a low diversity has been found within the Aculeatum group. This group is not commonly found in Africa and it has been hypothesized that it was created in Europe for ornamental purposes after crossing S. anguivi and S. aethiopicum group Kumba (Lester et al., 1986; Schippers, 2000), which would explain its low diversity.

Lester et al. (1986, 1990) reported that some accessions were intermediate in characteristics between $S$. anguivi and S. aethiopicum. In our case, we have found several of them, which presented some key traits used for classification that were typical 
of $S$. aethiopicum while others were characteristic of S. anguivi. These materials plotted between $S$. anguivi and S. aethiopicum, having some overlap with the latter. Intermediate forms may represent primitive or semi-domesticated weedy forms that are formed by occasional hybridization, as the area of natural distribution of the wild ancestor presents a high degree of overlapping with the area of distribution of the crop (Lester and Niakan, 1986; Lester et al., 1986, 1990). This intermediate forms very likely favor the flux of genes from the wild $S$. anguivi into the cultivated S. aethiopicum, contributing to a high genetic background and diversity.

Solanum macrocarpon accessions have also been very variable for the traits studied. An important diversity may be caused by the fact that in this crop some accessions are used for the leaves, others for the fruits, and others for both plant organs (Lester et al., 1990; Schippers, 2000; Maundu et al., 2009). Therefore, it is expected that accessions used for the leaves will have smaller fruits than those used for the fruits. Also, although a characteristic typical of S. macrocarpon is having fruits flattened or subspherical, an accession with elongated fruits has been found. It remains to be investigated if the elongated fruit of this odd accession is caused by a mutation similar to the SUN mutation of tomato, which results in extremely elongated fruits (Monforte et al., 2014).

The phenotypic results obtained have important implications for germplasm conservation and breeding (Furbank and Tester, 2011). The high diversity found indicates that a large number of accessions will need to be conserved in germplasm banks or represented in core collections in order to have a good representation of the phenotypic variation found in both species (Odong et al., 2013). The characterization data and the multivariate analysis performed may be useful to select a subset of accessions that represent most of the morphological diversity of both complexes. At the selection and breeding level, considerable phenotypic differences among and within groups may be used for selection of the best accessions or to select parents for obtaining F1 hybrids heterotic for yield or with intermediate or new characteristics (Lester and Thitai, 1989; Seck, 2000; Adeniji and Aloyce, 2012).

In conclusion, we have found that the combined utilization of conventional and Tomato Analyzer phenomics descriptors is a powerful tool for studying the diversity and relationships of scarlet and gboma eggplants complexes. In particular, Tomato Analyzer allows the detailed description of fruit characteristics and the differentiation of cultivar groups in which few plant morphological differences are found. The detailed characterization information on the germplasm collections will be useful for the enhancement of both crops, including the conservation of genetic resources, selection and breeding.

\section{ACKNOWLEDGMENTS}

This research has been partially funded by Ministerio de Economía y Competitividad and FEDER (grant AGL201234213). Pietro Gramazio is grateful to Universitat Politècnica de Valencia for a predoctoral fellowship.

\section{REFERENCES}

Adeniji, O. T., and Aloyce, A. (2012). Farmer's knowledge of horticultural traits and participatory selection of African eggplant varieties (Solanum aethiopicum) in Tanzania. Tropicultura 30, 185-191.
Adeniji, O. T., Kusolwa, P., and Reuben, S. O. W. M. (2012). Genetic diversity among accessions of Solanum aethiopicum L. groups based on morphoagronomic traits. Plant Genet. Resour. Characterization Utilization 10, 177-185. doi: 10.1017/S1479262112000226

Adeniji, O. T., Kusolwa, P., and Reuben, S. O. W. M. (2013). Morphological descriptors and micro satellite diversity among scarlet eggplant groups. Afr. Crop Sci. J. 21, 37-49.

Brewer, M. T., Lang, L., Fujimura, K., Dujmovic, N., Gray, S., and van der Knaap, E. (2006). Development of a controlled vocabulary and software application to analyse fruit shape variation in tomato and other plant species. Plant Physiol. 141, 15-25. doi: 10.1104/pp.106.077867

Brewer, M. T., Moyseenko, J. B., Monforte, A. J., and van der Knaap, E. (2007). Morphological variation in tomato: a comprehensive study of quantitative trait loci controlling fruit shape and development. J. Exp. Bot. 58, 1339-1349. doi: $10.1093 / \mathrm{jxb} / \mathrm{erl} 301$

Bukenya, Z. R., and Carasco, J. F. (1994). Biosystematic study of Solanum macrocarpon-S. dasyphyllum complex in Uganda and relations with S. linnaeanum. East Afr. Agric. Fores. J. 59, 187-204.

Dansi, A., Adjatin, A., Adoukonou-Sagbadja, H., Faladé, V., Yedomonhan, H., Odou, D., et al. (2008). Traditional leafy vegetables and their use in the Benin Republic. Genet. Resour. Crop Evol. 55, 1239-1256. doi: 10.1007/s10722-0089324-Z

Darrigues, A., Hall, J., van der Knaap, E., Francis, D. M., Dujmovic, N., and Gray, S. (2008). Tomato Analyzer-color test: a new tool for efficient digital phenotyping. J. Am. Soc. Hort. Sci. 133, 579-586.

Daunay, M. C., Lester, R. N., and Laterrot, H. (1991). "The use of wild species for the genetic improvement of brinjal-eggplant (Solanum melongena) and tomato (Lycopersicon esculentum)," in Solanaceae III: Taxonomy, Chemistry, Evolution, eds J. G. Hawkes, R. N. Lester, M. Nee, and N. Estrada (Kew: Royal Botanic Gardens), 389-412.

Edmonds, J. M. (2012). “Solanaceae," in Flora of Tropical East Africa, ed H. J. Beentje (Kew: Royal Botanic Gardens), 1-240.

Furbank, R. T., and Tester, M. (2011). Phenomics - technologies to relieve the phenotyping bottleneck. Trends Plant Sci. 16, 635-644. doi: 10.1016/j.tplants.2011.09.005

Furini, A., and Wunder, J. (2004). Analysis of eggplant (Solanum melongena)related germplasm: morphological and AFLP data contribute to phylogenetic interpretations and germplasm utilization. Theor. Appl. Genet. 108, 197-208. doi: 10.1007/s00122-003-1439-1

Gisbert, C., Prohens, J., Raigón, M. D., Stommel, J. R., and Nuez, F. (2011). Eggplant relatives as sources of variation for developing new rootstocks: effects of grafting on eggplant yield and fruit apparent quality and composition. Sci. Hort. 128, 14-22. doi: 10.1016/j.scienta.2010.12.007

Gonzalo, M. J., and van der Knaap, E. (2008). A comparative analysis into the genetic bases of morphology in tomato varieties exhibiting elongated fruit shape. Theor. Appl. Genet. 116, 647-656. doi: 10.1007/s00122-007-0698-7

Hurtado, M., Vilanova, S., Plazas, M., Gramazio, P., Herraiz, F. J., Andújar, I., et al. (2013). Phenomics of fruit shape in eggplant (Solanum melongena L.) using tomato Analyzer software. Sci. Hort. 164, 625-632. doi: 10.1016/j.scienta.2013.10.028

IBPGR. (1990). Descriptors for Eggplant. Rome: International Board for Plant Genetic Resources.

Khan, M. M. R., Hasnunnahar, M., and Isshiki, S. (2013). Production of amphidiploids of the hybrids between Solanum macrocarpon and eggplant. HortScience 48, 422-424.

Lester, R. N. (1986). Taxonomy of scarlet eggplants, Solanum aethiopicum L. Acta Hort. 182, 125-132.

Lester, R. N., and Daunay, M. C. (2003). Diversity of African vegetable Solanum species and its implications for a better understanding of plant domestication. Schriften zu Genetischen Ressour. 22, 137-152.

Lester, R. N., Hakiza, J. J. H., Stavropoulos, N., and Teixeira, M. M. (1986). "Variation patterns in the African scarlet eggplant, Solanum aethiopicum L.," in Infraspecific Classification of Wild and Cultivated Plants, ed B. T. Styles (Oxford: Clarendon Press), 283-307.

Lester, R. N., Jaeger, P. M. L., Bleijendaal-Spierings, B. H. M., Bleijendaal, H. P. O., and Holloway, H. L. O. (1990). African eggplants - a review of collecting in West Africa. FAO/IBPGR Plant Genet. Resour. Newsl. 81-82, 17-26.

Lester, R. N., Jaeger, P. M. L., and Child, A. (2011). Solanum in Africa. Birmingham: Celia Lester. 
Lester, R. N., and Niakan, L. (1986). "Origin and domestication of the scarlet eggplant, Solanum aethiopicum, from S. anguivi in Africa," in Solanaceae: Biology and Systematics, ed W. G. D’Arcy (New York, NY: Columbia University Press), 433-456.

Lester, R. N., and Thitai, G. N. W. (1989). Inheritance in Solanum aethiopicum, the scarlet eggplant. Euphytica 40, 67-74.

Little, T., and Hills, J. (1978). Agricultural Experimentation: Design and Analysis. New York, NY: Wiley.

Maundu, P., Achigan-Dako, E., and Morimoto, Y. (2009). "Biodiversity of African vegetables," in African Indigenous Vegetables in Urban Agriculture, eds C. M. Shackleton, M. W. Pasquini, and A. W. Drescher, (London: Earthscan), 65-104.

Monforte, A. J., Díaz, A. I., Caño-Delgado, A., and van der Knaap, E. (2014). The genetic basis of fruit morphology in horticultural crops: lessons from tomato and melon. J. Exp Bot. doi: 10.1093/jxb/eru017. [Epub ahead of print].

Odong, T. L., Jansen, J., van Eeuwijk, F. A., and van Hintum, T. J. L. (2013). Quality of core collections for effective utilisation of genetic resources review, discussion and interpretation. Theor. Appl. Genet. 126, 289-305. doi: 10.1007/s00122-0121971-y

Oyelana, O. A., and Ugborogho, R. E. (2008). Phenotypic variation of F1 and F2 populations from three species of Solanum L. (Solanaceae). Afr. J. Biotechnol. 7, 2359-2367.

Polignano, G., Uggenti, P., Bisignano, V., and Della Gatta, C. (2010). Genetic divergence analysis in eggplant (Solanum melongena L.) and allied species. Genet. Resour. Crop Evol. 57, 171-181. doi: 10.1007/s10722-009-9459-6

Prohens, J., Blanca, J. M., and Nuez, F. (2005). Morphological and molecular variation in a collection of eggplant from a secondary center of diversity: implications for conservation and breeding. J. Am. Soc. Hort. Sci. 130, 54-63.

Prohens, J., Plazas, M., Raigón, M. D., Seguí-Simarro, J. M., Stommel, J. R., and Vilanova, S. (2012). Characterization of interspecific hybrids and backcross generations from crosses between two cultivated eggplants (Solanum melongena and S. aethiopicum Kumba group) and implications for eggplant breeding. Euphytica 186, 517-538. doi: 10.1007/s10681-012-0652-x

Rodríguez, G., Strecker, J., Brewer, M., Gonzalo, M. J., Anderson, C., Lang, L., et al. (2010) Tomato Analyzer Version 3 User Manual. http://www.oardc. osu.edu/vanderknaap/files/Tomato_Analyzer_3.0_Manual.pdf.

Sánchez-Mata, M. C., Yokoyama, W. E., Hong, Y. J., and Prohens, J. (2010). $\alpha$-solasonine and $\alpha$-solamargine contents of gboma (Solanum macrocarpon L.) and scarlet (S. aethiopicum L.) eggplants. J. Agric. Food Chem. 58, 5502-5508. doi: $10.1021 /$ jf100709g
Schippers, R. R. (2000). African Indigenous Vegetables. An Overview of the Cultivated Species. Chatham: Natural Resources Institute.

Seck, A. (2000). Breeding procedures and results on indigenous vegetables: examples of African eggplant Solanum aethiopicum and okra Abelmoschus spp. Acta Hort. 522, 195-208.

Sekara, A., Cebula, S., and Kunicki, E. (2007). Cultivated eggplants - origin, breeding and genetic Resources, a review. Folia Hort. 19, 97-114.

Snedecor, G. W., and Cochran, W. G. (1989). Statistical methods, 8th Edn., Ames, IA: Iowa State University Press.

Spooner, D. M., Hetterscheid, W. L. A., van den Berg, R. G., and Brandenburg, W. A. (2003). Plant nomenclature and taxonomy: an horticultural and agronomic perspective. Hort. Rev. 28, 1-60.

Sunseri, F., Polignano, G. B., Alba, V., Lotti, C., Visignano, V., Mennella, G., et al. (2010). Genetic diversity and characterization of African eggplant germplasm collection. Afr. J. Plant Sci. 4, 231-241.

van der Weerden, G. M., and Barendse, G. W. M. (2007). A web-searchable database developed for the EGGNET Project and applied to the Radboud University Solanaceae database. Acta Hort. 745, 503-506.

Vorontsova, M., Stern, S., Bohs, L., and Knapp, S. (2013). African spiny Solanum (subgenus Leptostemonum, Solanaceae): a thorny phylogenetic tangle. Bot. J. Linn. Soc. 173, 176-193. doi: 10.1111/boj.12053

Conflict of Interest Statement: The authors declare that the research was conducted in the absence of any commercial or financial relationships that could be construed as a potential conflict of interest.

Received: 17 April 2014; accepted: 16 June 2014; published online: 07 July 2014.

Citation: Plazas M, Andújar I, Vilanova S, Gramazio P, Herraiz FJ and Prohens J (2014) Conventional and phenomics characterization provides insight into the diversity and relationships of hypervariable scarlet (Solanum aethiopicum L.) and gboma (S. macrocarpon L.) eggplant complexes. Front. Plant Sci. 5:318. doi: 10.3389/fpls. 2014.00318

This article was submitted to Crop Science and Horticulture, a section of the journal Frontiers in Plant Science.

Copyright (C) 2014 Plazas, Andújar, Vilanova, Gramazio, Herraiz and Prohens. This is an open-access article distributed under the terms of the Creative Commons Attribution License (CC BY). The use, distribution or reproduction in other forums is permitted, provided the original author(s) or licensor are credited and that the original publication in this journal is cited, in accordance with accepted academic practice. No use, distribution or reproduction is permitted which does not comply with these terms. 